\title{
Ditado Digital: um jogo para auxílio da escrita no Ensino Fundamental
}

\author{
Fernanda Nunes Deitos¹, Márcia Hafele Islabão Franco', André Peres ${ }^{1}$ \\ ${ }^{1}$ Instituto Federal de Educação, Ciência e Tecnologia do Rio Grande do Sul (IFRS) \\ CEP 90030 - 041- Porto Alegre - RS - Brazil \\ \{deitos.fe, mhislabao\}@gmail.com, andre.peres@poa.ifrs.edu.br
}

\begin{abstract}
This work approaches the tecnology applied to education from a dictation digital game. On this context, this work's goal is to assist the learning of writing and ortografy of elementary school students, approaching the benefit that the traditional dictation activity brings when inserted on the tecnological context. In this way, the article describes the development of the game, as well as its application and evaluation. As a result, the improvement of the writing besides the motivation, engagement and interest of the student by the dictation activity stands out.
\end{abstract}

\begin{abstract}
Resumo. O presente trabalho aborda a tecnologia aplicada à educação a partir de um jogo digital de ditado. Nesse contexto, o objetivo deste trabalho é auxiliar a aprendizagem da escrita e da ortografia de crianças do Ensino Fundamental I, abordando o benefício que a atividade tradicional do ditado traz ao ser inserida no contexto tecnológico. Dessa forma, o artigo descreve o desenvolvimento do jogo, bem como sua aplicação e sua avaliação. Como resultados, destaca-se o aprimoramento da escrita além da motivação, do engajamento e do interesse do aluno pela atividade do ditado.
\end{abstract}

\section{Introdução}

Sem dúvida uma das principais dificuldades encontradas no processo de ensinoaprendizagem, nos primeiros anos do Ensino Fundamental, concentra-se na área da linguagem, mais especificamente na consolidação da escrita. Dentre os recursos que o professor dispõe, capazes de desenvolver as habilidades de escrita nos alunos, encontra- se o ditado.

O ditado é capaz de constituir um recurso avaliativo, além de abordar a escrita e a ortografia de forma simples. Além disso, pode ser incluído em outras atividades e conteúdos da área da linguagem, sendo uma atividade muito utilizada nos primeiros anos do Ensino Fundamental.

Apesar dos benefícios que a utilização do ditado traz, Morais (2009) aponta que o mesmo pode carregar como ponto negativo o fato de o aluno se deparar com o erro e não o compreender como parte do processo de aprendizagem. Nesse sentido, o aluno pode ver-se frustrado ao conceber o erro como algo que é ruim. No entanto, de acordo com a concepção construtivista de Piaget (1970), este deve ser entendido como aspecto necessário para construir os conhecimentos.

Nesse cenário, este trabalho busca auxiliar o processo de ensino-aprendizagem da escrita através do uso do ditado em um jogo digital. Dessa forma, tornando uma atividade 
VII Congresso Brasileiro de Informática na Educação (CBIE 2018)

Anais do XXIX Simpósio Brasileiro de Informática na Educação (SBIE 2018)

tradicional, com o auxílio da tecnologia, em um recurso que possibilita despertar a motivação, o engajamento e o interesse dos alunos.

De acordo com Prensky (2012), o jogo traz a possibilidade de facilitar a aprendizagem através da interação e da motivação. Considerando que, em um jogo, o erro pode ser visto como uma etapa normal, que deve ser vencida, acredita-se que seja possível auxiliar os alunos na compreensão de que o erro faz parte deste processo.

O presente artigo está organizado da seguinte forma: a Seção 2 apresenta a prática escolar do ditado; a Seção 3 aborda o erro na concepção construtivista do processo de aprendizagem; os jogos sérios digitais e seus benefícios para a aprendizagem são abordados na Seção 4; a Seção 5 apresenta os trabalhos relacionados; a Seção 6 mostra o jogo do ditado digital; a Seção 7 descreve o material e os métodos utilizados nesta pesquisa; a Seção 8 apresenta os resultados obtidos e, por fim, a Seção 9 expõe as considerações finais.

\section{2. $O$ ditado e seus elementos}

Segundo Chartier (1998), o ditado surge a partir da metade do século XIX, com o objetivo não só de alfabetização, como ensino da leitura e da escrita, mas também de aquisição da cultura da escrita, preocupando-se com a ortografia. O ditado é concebido como uma atividade capaz de complementar as demais, visando à escrita e a ortografia como seus maiores objetivos, como aponta Hébrard (2001) ao destacar que a partir do ditado são propostos diversos exercícios.

Com relação aos objetivos e benefícios do ditado no processo de alfabetização, percebe-se que essa atividade aparece como eixo desse processo, pois de acordo com Peres (2012) o ditado possibilita atividades centrais na aprendizagem da leitura e da escrita.

Ao referir-se ao ditado como uma atividade tradicional se faz referência ao modo tradicional como esta atividade vem sendo utilizada ao longo do tempo. Como sustenta Morais (2009, p.61) ao trazer que os professores "(...) têm o ditado como atividade preferida para 'ensinar' ortografia".

\section{O construtivismo e o erro no processo de aprendizagem}

A teoria construtivista é baseada nas ideias do suíço Jean Piaget. Segundo Azenha (2001) a essência dos questionamentos que incentivaram os estudos de Piaget foi pensar sobre o que é o conhecimento e como se chega a ele. Na concepção do construtivismo quanto ao processo educativo, o aluno é visto como protagonista e o conhecimento é visto como um processo que se constrói e reconstrói pelo indivíduo que está aprendendo.

Nesse cenário de desenvolvimento da constituição do conhecimento, os alunos ainda precisam lidar com diversos aspectos que podem ser vistos como problemas. Um deles refere-se aos danos que o erro causa na aprendizagem, pois o mesmo, segundo Demo (2001, p.50) precisa ser compreendido como parte do processo de aprendizagem. Partindo da concepção construtivista, como traz Ferreiro (1994), o erro faz parte deste processo e ele não deve ser apontado, mas sim ser compreendido, encontrando suas razões.

Na concepção de Piaget o erro deve ser utilizado como um meio de se construir a aprendizagem e nesse sentido é papel do professor buscar recursos em que o erro seja visto como um meio de se chegar ao acerto (La Taille, 1997). Dessa forma, o professor deve propor ao aluno situações onde este deva resolver problemas, provocando o desequilíbrio, para que este seja capaz de constituir novos pensamentos de maneira construtiva, a fim de que o erro seja superado.

\section{Os Jogos Sérios Digitais}


VII Congresso Brasileiro de Informática na Educação (CBIE 2018)

Anais do XXIX Simpósio Brasileiro de Informática na Educação (SBIE 2018)

O termo "jogos sérios" refere-se aos jogos que apresentam objetivos relacionados à aprendizagem de algum conteúdo instrucional (SILVA, 2012). Os jogos sérios digitais (JSD) são uma estratégia de ensino capaz de alcançar diferentes objetivos, pois dispõem de recursos ricos para desenvolver as habilidades necessárias para as aprendizagens das áreas do conhecimento (GRÜBEL; BEZ, 2006, p.6).

Segundo Savi e Ulbricht, (2008) para que os jogos digitais sejam considerados como educacionais, além de conterem suas características principais, devem estar presentes aspectos relacionados às aprendizagens. Essa aprendizagem acontece através desses aspectos que o jogo carrega e que por isso, devem ser considerados recursos pedagógicos tão importantes quanto os tradicionais. Além disso, dispõe aos alunos possibilidades inovadoras de aprender com diferentes técnicas podendo auxiliar os diferentes tipos de aprendizagens que os sujeitos possuem (SAVI, 2008).

Prensky (2012) enumera os motivos que satisfazem a aprendizagem através dos jogos digitais. O primeiro, chamado de "envolvimento", acontece pelo fato da aprendizagem estar ligada ao recurso do jogo e assim ser capaz de motivar. O segundo motivo está relacionado ao processo interativo de aprendizagem, onde há um engajamento na participação devido às diferentes formas de se jogar. E, o terceiro motivo, a forma como jogo e o ensino devem se completar a partir de diferentes formas de aplicação.

\section{Trabalhos Relacionados}

Oliveira et al (2013) trazem o software educacional ditado digital para a web. O mesmo é desenvolvido na linguagem PHP (Hypertext Preprocessor) e tem como função ajudar os professores de português que atuam no Ensino Fundamental I, no que diz respeito à ortografia. Neste software, são utilizados recursos multimídia, onde há a associação com a imagem para auxiliar na escrita. Ainda é possível que o aluno possa ouvir o áudio da palavra ou solicitar uma nova palavra quando não souber escrever. Também é possível que o professor administre e cadastre as palavras e monitore os resultados através de relatórios exibidos a partir de gráficos.

Silva, Silva e Melo (2017) trazem o aplicativo adoletras, que tem como objetivo auxiliar no processo de alfabetização abordando recursos da realidade aumentada ao se ter uma interação entre objetos e ambientes virtuais. O aplicativo é composto de três fases sendo elas: parque, zoológico e praia. Nas fases existem desafios referentes à grafia das palavras.

Faria e Colpani (2017) trazem o software "Joy e as letrinhas". O jogo acontece a partir de dois personagens, em que o principal seria o "professor Joy", e sua tutora a "Professora Angélica". O papel da tutora é auxiliar, dando o direcionamento das ações em cada cenário. $\mathrm{O}$ jogo tem como foco trabalhar com a imaginação a partir de cores, cenários e personagens. $\mathrm{O}$ conteúdo tem relação com a ordenação de vogais e escrita de palavras através das sílabas. O jogo é composto de fases com objetivos como, por exemplo, completar o alfabeto utilizando as vogais. Há também um feedback para que o aluno possa memorizar a ordem do alfabeto de forma lúdica. A partir do jogo e possível que o professor reconheça os alunos que ainda não conhecem a ordem do alfabeto ou suas letras e também serve para incentivar o conhecimento das consoantes. Com o passar das fases novas atividades são solicitadas e o jogador continua recebendo feedback emáudio e vídeo.

Essa seção apresentou um breve levantamento dos trabalhos relacionados, com o objetivo de destacar características que contribuíram com o desenvolvimento do jogo do ditado digital, como a questão dos desafios apresentados nos jogos. Nessa pesquisa, houve a participação dos alunos no desenvolvimento do jogo, o que caracteriza um diferencial 
VII Congresso Brasileiro de Informática na Educação (CBIE 2018)

Anais do XXIX Simpósio Brasileiro de Informática na Educação (SBIE 2018)

em relação aos outros. Além disso o público alvo do jogo se apresenta como uma especificidade, pois é indicado para o último ano do ciclo de alfabetização, em que os alunos têm como objetivo a consolidação de sua escrita.

\section{Jogo do Ditado Digital}

O jogo "Ditado Digital" está inserido na área de conhecimento da linguagem, pois visa contribuir para as aprendizagens relacionadas à escrita de palavras e regras ortográficas, no intuito de auxiliar no processo de consolidação da escrita. $\mathrm{O}$ mesmo pode ser utilizado como recurso facilitador em sala de aula, auxiliando os professores na complementação e interação dos conteúdos escolares.

O jogo foi desenvolvido a partir do software Twine (2018), disponível gratuitamente, e que é usado para criação de histórias. Ele pode ser adaptado para diferentes objetivos, como interpretação de texto, escrita espontânea e ortografia. O jogo busca despertar o interesse dos alunos e instigar sua participação efetiva, além de abordar o erro de forma natural.

As palavras utilizadas no jogo foram escolhidas com o auxílio da professora da turma em que foi aplicado e com base nas necessidades ortográficas dos alunos, utilizando em geral palavras contendo dígrafos consonantais. As palavras podem ser modificadas de acordo com as necessidades dos alunos, porém devem adequar-se ao cenário em que estão inseridas.

\section{Material e Métodos}

A presente pesquisa configura-se como uma pesquisa de natureza aplicada, pois, há uma aplicação prática com o objetivo de resolução de um problema (MARCONI; LAKATOS, 2015, p. 6-7). Nesse cenário, este trabalho está inserido no campo da pesquisa-ação, pois tem como base "o estudo de uma situação social com vistas a melhorar a qualidade da ação dentro dela" (ELLIOT, 1991, p. 69). Neste caso, os participantes da pesquisa são alunos do terceiro ano do Ensino Fundamental, de uma escola da rede pública da cidade de Porto Alegre.

No desenvolvimento deste trabalho foram realizadas as seguintes etapas: i) desenvolvimento e aplicação do protótipo em papel; ii) análise dos dados observados na aplicação do protótipo em papel; iii) desenvolvimento e aplicação do jogo; e iv) validação.

A aplicação do protótipo em papel e do jogo do ditado, foram realizados através de dois experimentos, que foram conduzidos pela pesquisadora e acompanhados pela professora da turma, e contou com a participação de 20 alunos com idades entre 7 e 8 anos. Os sujeitos da pesquisa foram escolhidos de acordo com a faixa etária necessária para realização da aplicação do jogo, por se enquadrarem no último ano do ciclo de alfabetização. Além disso, de acordo com a natureza desta pesquisa e considerando os princípios éticos que envolvem seres humanos, a mesma apresenta aprovação pelo Comitê de Ética em Pesquisa envolvendo seres humanos (2.650.728). Os experimentos realizados serão descritos nas próximas duas subseções

\subsection{Primeiro Experimento}


VII Congresso Brasileiro de Informática na Educação (CBIE 2018)

Anais do XXIX Simpósio Brasileiro de Informática na Educação (SBIE 2018)

O primeiro experimento tinha por objetivo fazer com que os alunos avaliassem a interface e a estrutura das atividades do jogo. Inicialmente foram entregues para cada aluno os protótipos do jogo em papel, para que eles avaliassem com suas impressões. O intuito dessas observações era adquirir o maior número de informações sobre a avaliação dos alunos.

De acordo com Preece, Rogers e Sharp (2013) o protótipo é a manifestação de um design que permite interagir e explorar sua adequação, sua construção tem como função a experimentação de ideias e novas versões. Considera-se como a questão mais importante em um protótipo, identificar se o projeto está indo na direção certa, para isso, a avaliação e o feedback são fundamentais.

Optou-se por utilizar um protótipo em papel, denominado prototipação de baixa fidelidade (PREECE; ROGERS; SHARP, 2013), pelo fato de ser uma alternativa rápida, de fácil acesso e custo baixo. A prototipação foi importante pois possibilitou o envolvimento dos alunos no processo de desenvolvimento do jogo.

Durante o primeiro experimento, foi explicado aos alunos a importância da participação deles na avaliação do protótipo do jogo e foram dadas as instruções de que os cenários ilustrados na folha de papel representariam a tela do computador e que eles poderiam utilizar um lápis como auxílio, para realizar o papel de mouse. A pesquisadora anotou as respostas, sem interferir ou induzir os participantes.

A análise foi realizada individualmente com os 20 alunos. Cada aluno foi incentivado a pensar sobre a interface do jogo através de perguntas previamente estipuladas. A primeira tela do protótipo, ilustrada na Figura 1, foi apresentada aos alunos e logo após foram realizadas as seguintes questões: 1) o que você observa nesta tela? 2) do que você acha que se trata?

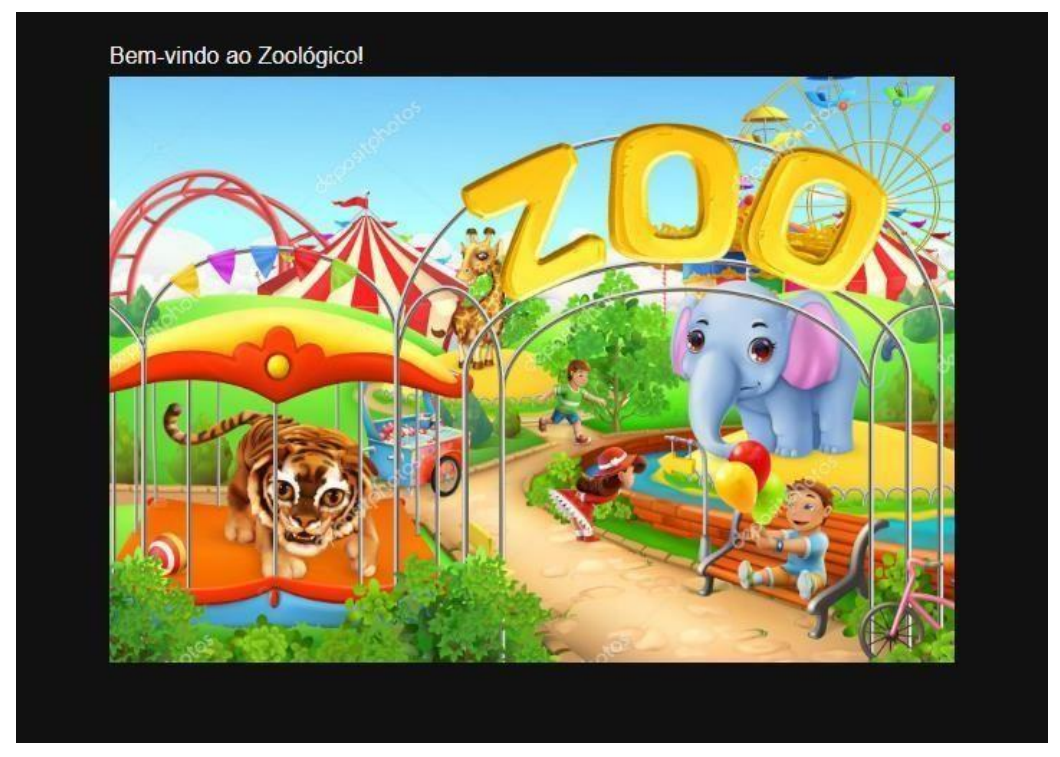

Figura 1. Tela inicial do jogo

$\mathrm{Na}$ segunda tela, foram apresentados aos alunos os personagens do jogo, que deviam ser escolhidos por eles. Nessa observação foram realizados os seguintes questionamentos: 1) o que você observa nesta tela? 2) qual a função do menino e da menina? 3) você gostaria de ter mais opções de escolha? (referindo-se aos personagens). 
VII Congresso Brasileiro de Informática na Educação (CBIE 2018)

Anais do XXIX Simpósio Brasileiro de Informática na Educação (SBIE 2018)

A terceira tela do protótipo, observada na Figura 2, foi apresentada aos alunos, com as seguintes questões: 1) o que você observa nesta tela? 2) do que você acha que se trata? 3) do que você mais gostou? 4) do que você menos gostou?

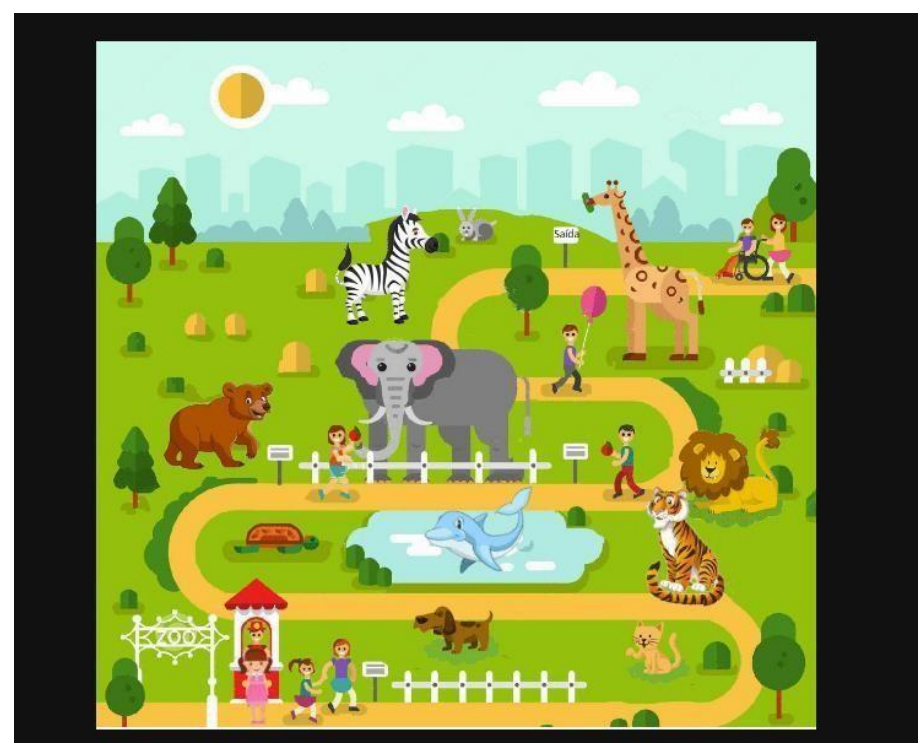

Figura 2. Tela referente ao animal que o aluno deve escrever

As próximas telas que foram apresentadas aos alunos ilustravam os animais, como apresenta a Figura 3. As indagações realizadas foram: 1) o que você acha das cores apresentadas? 2) quais cores você gostaria que as atividades apresentassem? 3) o que você acha das figuras apresentadas? 4) o que você acha que deve ser feito?

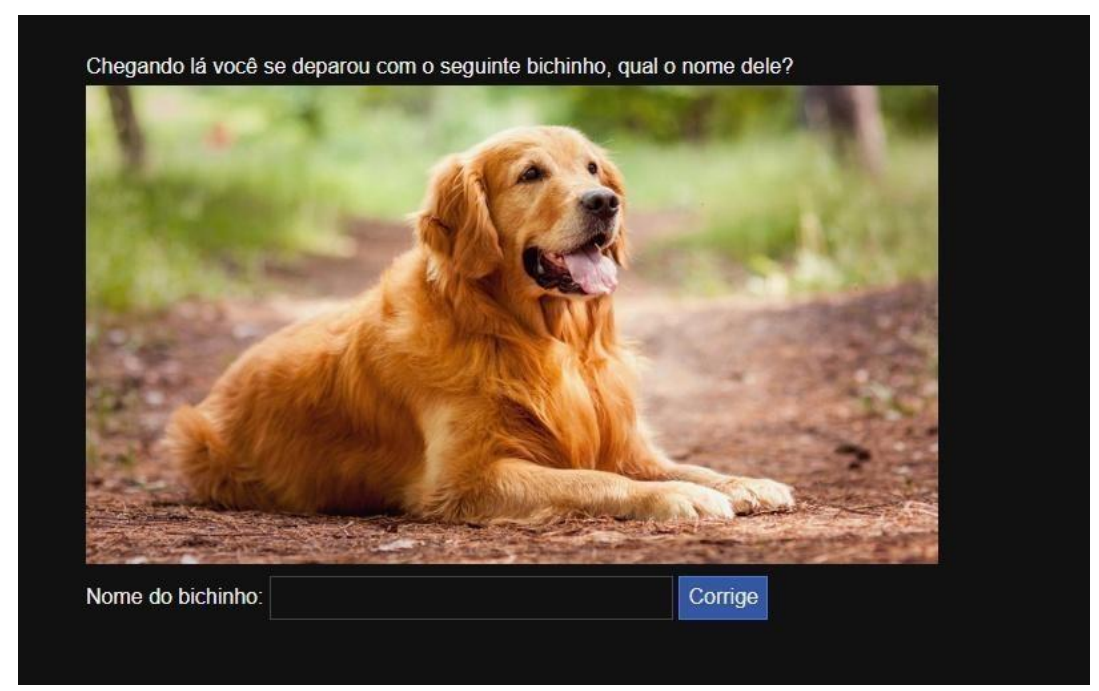

Figura 3. Tela referente à escrita

A partir dessas observações e dos questionamentos, foram realizados os ajustes necessários no jogo e, posteriormente, ocorreu o segundo experimento através da aplicação do jogo.

\subsection{Segundo Experimento}


VII Congresso Brasileiro de Informática na Educação (CBIE 2018)

Anais do XXIX Simpósio Brasileiro de Informática na Educação (SBIE 2018)

O segundo experimento ocorreu um mês após a realização do primeiro. A aplicação do jogo aconteceu na sala de informática da escola, onde havia 20 computadores e teve a participação de todos os 20 alunos da turma. Inicialmente foi informado aos alunos que eles utilizariam o jogo do ditado e ao final da atividade avaliariam o jogo respondendo três perguntas. Foi exposto no quadro uma explicação dessa avaliação a partir da escolha das "carinhas", representando as emoções. Como os alunos ainda não estão alfabetizados, considera-se essa forma de representação a mais adequada. Sendo assim, a "carinha feliz" representa "bom", a "carinha indiferente" representa "regular" e a "carinha triste" representa "ruim".

A análise da contribuição do jogo para a aprendizagem da escrita e ortografia dos alunos foi realizada através do MEEGA+ (Model for Evaluating Educacional Games) (SAVI, 2011). Esse modelo de avaliação de jogos foi proposto por Savi (2011), sendo construído com base nas teorias de design instrucional e educação. $\mathrm{O}$ modelo foi escolhido por ser construído com base em uma escala que mede variáveis que não se manifestam e que podem adequar-se às funcionalidades do jogo do ditado digital, sendo estas: motivação e aprendizagem.

\section{Resultados e Discussão}

A partir da análise dos resultados obtidos no primeiro experimento, foi possível perceber que todos os vinte (20) alunos conseguiram compreender que se tratava de um jogo e que o mesmo acontecia em um zoológico, onde os nomes dos animais deveriam ser escritos. Quanto aos personagens, os vinte (20) alunos conseguiram compreender que era necessário escolher um personagem para jogar. Sobre outras opções de personagens, quinze (15) alunos gostariam de ter mais opções e alguns deles deram sugestões de quais personagens poderia haver. Doze (12) alunos perceberam que o jogo era apresentado em uma espécie de tabuleiro, onde se tinha um caminho a percorrer, com o objetivo de chegar até a saída. Oito (8) alunos destacaram que uma das figuras dos animais estava muito pequena em relação às outras. Sete (7) alunos destacaram que a cor do fundo era muito escura e que preferiam uma cor mais clara.

Durante o segundo experimento, observou-se o entusiasmo e a motivação dos alunos com a atividade, ainda mais por ser uma atividade a ser realizada no laboratório de informática, espaço que não é comumente utilizado com as turmas do Ensino Fundamental I. A presença de um novo espaço e de uma atividade diferenciada, como no caso do jogo, motivaram esses alunos na participação. Muitos deles demonstraram a vontade de ter este tipo de atividade no seu cotidiano de sala de aula.

Após a primeira tentativa de cada um, foi permitido que os alunos jogassem novamente, pois se mostraram muito empolgados com a novidade e também foi possibilitado que pudessem jogar em duplas, para um auxiliar o outro e trocar as suas impressões. Percebeu-se que ao se realizar o jogo em duplas, os alunos que tinham maior facilidade na escrita das palavras auxiliaram os que apresentavam alguma dificuldade. Porém, estes alunos não davam as respostas prontas, eles ajudavam os colegas a perceber qual era o som da letra.

O segundo experimento possibilitou compreender o quanto este tipo de atividade mostrou a cooperação entre os alunos, sem que houvesse uma competição. Esta cooperação oportuniza que o aprendizado seja construído de maneira coletiva e a partir 
VII Congresso Brasileiro de Informática na Educação (CBIE 2018)

Anais do XXIX Simpósio Brasileiro de Informática na Educação (SBIE 2018)

da troca de experiências. Freinet (1998b) rejeitava a competição individual, defendendo a ideia da ajuda mútua na experiência coletiva, proporcionando uma aprendizagem crítica (FREINET, 1998a).

Percebeu-se que, mesmo os alunos que avaliaram como negativa sua escrita das palavras, avaliaram o jogo como "bom" e apresentaram a vontade de realizar o mesmo novamente. Nesse sentido, acredita-se que mesmo com a dificuldade, o fato de ser um jogo apresentou aos alunos a vontade de prosseguir para finalizar a atividade e conseguir realizar a escrita correta. Foi destacado pela professora que estes mesmos alunos são os que mais apresentam aversão ao ditado tradicional.

As perguntas realizadas aos alunos ao final do jogo, no segundo experimento, foram: 1) Como você se sentiu ao participar desse jogo? 2) Se você tivesse que jogar novamente, como se sentiria? 3) Em relação à escrita, como você se sentiu? A primeira pergunta foi pensada para verificar o nível de satisfação do jogo, a segunda tem relação com o grau de motivação que o jogo proporcionou e a terceira para verificar como os alunos se sentiram em relação ao conteúdo do jogo.

Observou-se no segundo experimento que nove (9) alunos apresentaram mais rapidez ao concluir a atividade. Estes alunos foram os que obtiveram de $90 \%$ a $100 \%$ de acertos na sua primeira tentativa e avaliaram o jogo, tanto em relação à motivação, quanto na parte da escrita, como "bom". Entre os outros onze (11) alunos, seis demoraram um pouco mais, porém conseguiram completar o jogo sem muitas dificuldades. Os outros cinco (5) alunos apresentaram dificuldades na escrita de palavras e usaram o recurso da correção mais vezes. Estes cinco (5) alunos avaliaram a escrita das palavras como "ruim", porém o jogo foi avaliado como "bom".

Após a análise dos resultados, algumas das características do jogo foram modificadas, por exemplo, a cor utilizada no fundo, o estilo e cor das letras, conforme apresentado na Figura 4.

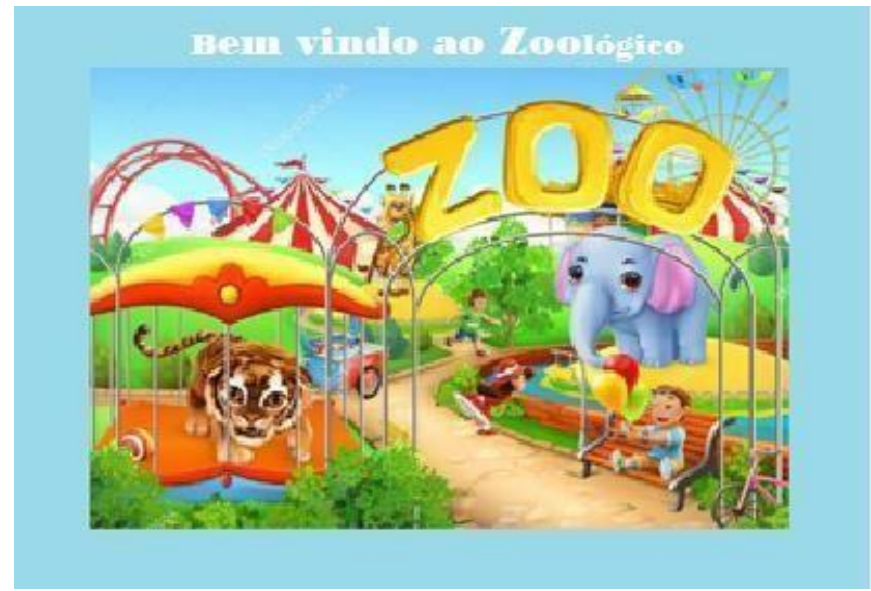

Figura 4. Tela do jogo após sugestões dos alunos

Através dos dois experimentos realizados, observou-se claramente os três motivos, definidos por Prensky (2012), que satisfazem a aprendizagem através dos jogos digitais, sendo estes: i) envolvimento - a aprendizagem da escrita e da ortografia estão ligadas ao recurso do jogo do ditado digital; ii) processo interativo - no engajamento dos 
VII Congresso Brasileiro de Informática na Educação (CBIE 2018)

Anais do XXIX Simpósio Brasileiro de Informática na Educação (SBIE 2018)

alunos em realizar as atividades no jogo; iii) a forma como o jogo e o ensino se completam a partir das diferentes formas aplicação.

\section{Considerações Finais}

Este trabalho buscou abordar a atividade do ditado de uma forma diferente da tradicional, que é frequentemente utilizada na escola. Pensando em inserir essa prática escolar no contexto tecnológico, pretendeu-se que os alunos pudessem compreender o erro como parte do processo de aprendizagem, visto que em um jogo, errar é tido como algo natural, assim como traz Prensky (2012).

Nesse sentido, ao ser dado um novo olhar para essa atividade, foi possível promover maior participação e engajamento dos alunos tanto na participação do jogo em si, quanto na vontade de finalizá-lo ao encontrar a escrita correta das palavras e assim poder trabalhar o conteúdo da ortografia de outra maneira. Dessa forma, mesmo com a presença dos erros, os alunos mostraram-se motivados com o jogo e em buscar os seus acertos, como visto na concepção construtivista de Piaget (1970).

Sendo assim, com a aplicação desse jogo, foi possível perceber que o erro foi concebido de maneira construtiva. Visto que foi a partir dos erros na escrita das palavras que os alunos puderam persistir engajados em finalizar o jogo e escrever as palavras corretamente. Dessa forma a aprendizagem da escrita e da ortografia pode ser aprimorada, possibilitando ao aluno a sistematização da aprendizagem ao refletir sobre seu erro, sendo capaz de elaborar conceitos e, assim, construir seu aprendizado. Sem medo de errar o aluno se permite realizar tentativas para encontrar o acerto e avançar, não só no jogo como em seu processo de aprendizagem.

\section{Referências}

AZENHA, M. G. (2001) “Construtivismo: de Piaget a Emilia Ferreiro”. 7 ed. São Paulo, SP: Ática.

CHARTIER, Roger. (1998) "A aventura do livro: do leitor ao navegador. Conversações com Jean Lebrun”. Tradução de Reginaldo Carmello Corrêa de Moraes. São Paulo: Imprensa Oficial do Estado de São Paulo: UNESP.

DEMO, P.E. É errando que a gente aprende. Nova Escola. São Paulo, n.144, pp.49-51, ago. 2001.

ELLIOT, J. Action research $\mathrm{f}$ Action research for educational change. tional change Filadélfia: Open University Press, 1991.

FARIA, Mateus José de; COLPANI, Rogério. (2017) "Joy e as letrinhas: um Serious Game como ferramenta de auxílio no processo de alfabetização de crianças do ensino fundamental". Revista Brasileira de Informática na Educação - RBIE. v. 25, No 2.

FREINET, Cèlestin. (1998a) “Educação pelo trabalho”. São Paulo: Martins Fontes.

.(1998b) "Ensino de psicologia sensível”. São Paulo: Martins Fontes.

GRÜBEL, Joceline M.;BEZ, Marta R. (2006) "Jogos Educativos" Instituto de Ciências Exatas e Tecnológicas - Centro Universitário Feevale. v. $4 \mathrm{n}^{\circ}$ 2, dez.

HÉBRARD, Jean. (2001) "Por uma bibliografia material das escritas ordinárias: o espaço gráfico do caderno escolar (França - Séculos XIX e XX)". In: Revista Brasileira de 
VII Congresso Brasileiro de Informática na Educação (CBIE 2018)

Anais do XXIX Simpósio Brasileiro de Informática na Educação (SBIE 2018)

História da Educação. n. 1,jan./jun. p. 115-141.

LA TAILLE, Y. de. (1997) “O erro na perspectiva piagetiana”. In: AQUINO,J. G. (Org.) Erro e fracasso na escola: alternativas teóricas e práticas. São Paulo: Summus, p. 2545 .

MARCONI, M. de A, LAKATOS, E. M. (2015) “Técnicas de pesquisa:planejamento e execução de pesquisas, amostragens e técnicas de pesquisa, elaboração, análise e interpretação de dados”. 2015.

MORAIS, Artur Gomes de. (2009) “Ortografia: ensinar e aprender”. 5. ed. São Paulo: Ática.

PERES, Eliane. (2012) "Um estudo da História da Alfabetização através de cadernos escolares (1943-2010)”. In: Cadernos de História da Educação. v. 11, n. 1, jan./jun. p. 93-106.

PIAGET, J.(1970) “ O nascimento da inteligência na criança”. 7.ed. Neuchatel, Delachaux et Niestlé.

PREECE, J., ROGERS, Yvone, SHARP, Helen. (2013) “Design de Interação - Além da Interação Homem-computador" - $3^{\text {a }}$ Ed.

PRENSKY, Marc. (2012) “Aprendizagem baseada em jogos digitais”. São Paulo: SenacSP.

SAVI, Rafael; ULBRICHT, Vania Ribas. (2008) Jogos digitais educacionais: benefícios e desafios. RENOTE, v. 6, n. 1.

SAVI, Rafael. (2011) "Avaliação de jogos voltados para a disseminação de conhecimentos". 238p. tese (Doutorado). Universidade Federal de Santa Catarina, Florianopolis.

SILVA, Tatyane Souza Calixto da; SILLVA, Amanda Souza Calixto da; MELO, Jeane Cecília Bezerra de. (2017) "Adoletras: Um jogo de Realidade Aumentada para auxiliar no processo de Alfabetização”. In: Congresso Brasileiro de Informática na Educação.

SILVA, T. G. (2012) "Jogos Sérios em Mundos Virtuais: uma abordagem para o ensinoaprendizagem de Teste de Software". Dissertação de Mestrado. Programa de PósGraduação em Informática. Universidade Federal de Santa Maria.

Twine. Twine,(2018) Disponível em: <<http://twinery.org/>>. Acesso em: 15 mar. 